\title{
A Selective History of Internet Technology and Social Work Stephen M. Marson
}

From a base of unintended consequences, this article illustrates how the Internet's original purposes have been employed by social work professionals, especially those in academic settings and professional associations. It first reviews the military roots of the Internet and its salient features which on the surface appear contrary to traditional social work values. It then reviews how social work professionals have employed the Internet, offers guidelines, and makes recommendations to other professionals. Due to space restrictions, Internet history and its use by social work professionals outside of the USA is not addressed.

The Internet is often described as "organized chaos." We can use the same words to describe the history of the internet in tracing linkage among: the military agenda, astounding engineering feats, online social interaction action, and social work education and practice. Within the context of "chaos," one must appreciate that if it were not for the distinct possibility of complete nuclear annihilation during the cold war, there may have been no Internet! American paranoia of Communism reached its zenith immediately following the success of Sputnik. The Eisenhower Administration pursued a fail-safe communications system (which led to what is known now as the Internet). During a nuclear holocaust, military experts knew that communications systems would be wiped out. Military experts needed a communications system that could evoke the delivery of nuclear warheads and defend against the entry of warheads (Salus, 1995).

\section{UNINTENDED CONSEQUENCES OF MILITARY REQUIREMENTS}

Although this history has many streams of thought, our focus must be on the U.S. Department of Defense's [DoD] funding of ARPANET. ARPA is an acronym for Advanced Research Projects Agency [later renamed Defense Advanced Research Projects Agency or DARPA]. NET, of course, is short for “network.” Beginning their work in 1969, ARPANET's teams of hardware and software engineers configured four computers as an experimental network. These computers were located at:

Stanford Research Institute

University of California at Los Angeles

University of California at Santa Barbara

University of Utah

Bolt, Beranek, and Newman Inc. [BBN] coordinated the experiment and was awarded several contracts by the DoD. BBN built the first Interface Message Processors [IMP]. The IMP is the mother of the often heard Internet jargon, “File Transfer Protocol.” On September 2, 1969, IMPs were first used with intermittent success to transfer information among these major research institutions. ${ }^{1}$

On October 1972 in Washington, DC, the first International Conference on Computers and Communities was convened. Here, over 1,000 attendees witnessed the first public display of ARPANET (Bolt, Beranek \& Newman, 1981). Tolhurst et al. (1994) described the demonstration as flawless, but the behind the scenes preparations bordered on comical. The network was not operational until seconds prior to the presentation. Yet, every observer was profoundly impressed with the demonstration. Some

\footnotetext{
${ }^{1}$ Although Salus (1995) confirms that Internet designers work through the night, weekends and holidays, humorous elements existed. Several engineers wrote poems to commemorate the 20th anniversary of the first IMP. These poems are worth the time to read and can be found in Salus (1996, p. 11 - 16).
} 
thought it has been fully functional for years! "The flawless demonstration so impressed the attendees that they returned to their research centers with a vision of the promise of greater things to come” (p. 29). Tolhurst et al. (1994) is accurate, but the science behind the development of the Internet was sloppy! Yet, any professor of research methods knows that the mother of cutting edge research is unleashed and sometimes undisciplined creativity.

Three technical advances created the evolution of ARPANET to the Internet. First was the development of the Transmission Control Protocol/Internet Protocol [TCP/IP]. TCP/IP was more userfriendly than its predecessor [NCP-Network Control Program]. Second, Xerox completed a long series of experiments that led to the development of the EtherNet. Third, in an effort to maximize the use of the network among institutions of higher education, DARPA established a contract with BBN and the University of California at Berkeley to invent a low-cost TCP/IP. Berkeley is credited with the allfamiliar File Transfer Protocol [FTP] and c-mail. By 1975, engineers and computer scientists were beginning to learn the practical applications of the network-and the problems.

\section{INCREASING TRAFFIC, REGULATION AND ONLINE SOCIAL INTERACTION}

By the early 80s, the network traffic increased to the point of becoming sluggish. As a result, in 1983 ARPANET was split. MILNET was used for military sites and ARPANET was used for nonmilitary traffic. However, it did not take long for growth to go beyond control a second time. To deal with the unceasing growth, standardized protocols were required by the Secretary of Defense. Unknown at the time, these standardizations laid the ground work for the successful commercialization of the Internet. Utilizing these standards, the National Science Foundation funded or partially funded six supercomputer centers known as NSFNET. These centers merged into a backbone of the Internet.

NSFNET permitted an easier access in order for researchers to share their ideas in a more userfriendly environment. Time could be spent developing scientific ideas rather than spending countless hours figuring out the network. A key innovation occurred with Paul Mockapetris's (University of Southern California) November 1983 memo entitled “Domain Name System."' To compensate for the unexpected increase of addresses, he proposed an international system which includes seven "top-level domains":

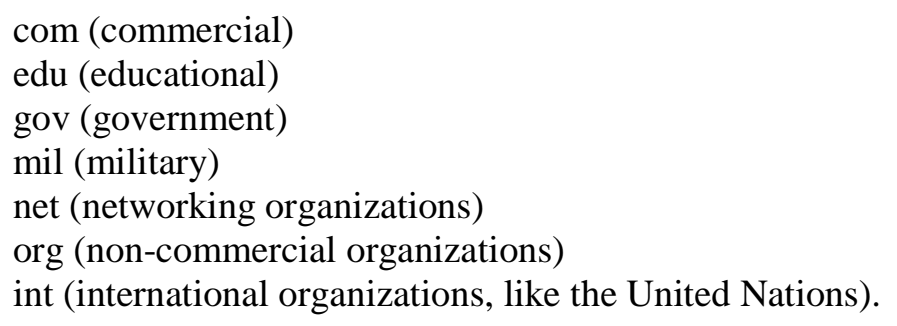

Three-letter county codes were added later. This was a complex political task, not an engineering problem.

By 1992, the Internet had continued to grow without any controls. No single entity could claim authority. The real success of the Internet is not attributed to the various technical consortia but consistently is attributed to "cooperation" among the users. When one person or a group violates the boundary of reasonableness, users work together to establish a position. Observances of Internet activity are an irreplaceable social psychology laboratory.

Two extremely different behavioral forces on the Internet set the tone for legislative control. First, Stoll's (1989) The Cuckoo's Egg discusses the most cited and most exciting problem that emerged from the Internet. Stoll describes how he stumbled into a ring of eastern block spies. The process of 
his discovery and cooperation has inspired the Internet community. On the other extreme and dark side of the Internet, we have the case of the Internet worm. Burstyn (1990) outlines the actions and consequences of Robert Morris, son of a scientist of the National Security Agency's Computer Security Council, and a Cornell graduate student. He developed a computer program that could have clogged the entire Internet. Although he claimed his action was an accident and that he had no ill intentions, he received a three-year sentence. No physical damage was inflicted nor was any information lost, but many human and computer hours were spent in a network clean-up. Schmidt and Darby (n.d./1997) state that the effect of the worm was devastating while Burstyn (1990) estimates that approximately $10 \%$ of computers connected to the Internet were affected. The most serious problem was the interruption of the Army's Ballistic Research Laboratory which stayed off the Internet for a week. The most important outcome was federal legislation concerning criminal acts on the Internet. Congress wanted to send a message to pranksters and saboteurs. Thus, Morris's action induced a precedent for legal control of the Internet, while Stoll's experiences encouraged lawmakers to refrain from over-involvement. Congress faced a paradox. They realized the need for legislation for damage control, but desired the rich contributions made in an atmosphere of organized chaos.

The above discussion illustrates that the history of the Internet is a history of rapid technological improvements wed to an environment of human cooperation. The technological advances and social linkages occurred in three general categories that are not necessarily mutually exclusive. ${ }^{2}$ They include:

- Communication

E-Mail

InterNIC

Listserv

Chat

- Information Acquisition

Archie

Bulletin Board

Gopher

Hytelnet

UseNet NewsGroups

Veronica

WAIS

World Wide Web

- Other

File Transfer Protocol

Telnet

Perhaps the most exciting of the above list is the World Wide Web [WWW or Web]. WWW has gained more national and international attention than all the other Internet services combined. The WWW is a network of Internet sites that use a common site identification system and common language for displaying information organized by Web pages. In 1989, the first Web page was developed under the sponsorship of the European Laboratory for Particle Research (the combined resources of 18 countries). The first Web navigation software was far from user-friendly. It was run on UNIX-based computers and little thought was given to PC-based machines.

As soon as Mosaic was written in 1993 by students (Marc Andreessen and Eric Bina) at the National Center for Supercomputing Applications (University of Illinois at Urbana-Champaign), a new

\footnotetext{
${ }^{2}$ Each of these are defined in the glossary with other terms.
} 
computer milestone emerged. The WWW exploded into popularity because Mosaic is a user-friendly and intuitive software that could be adapted for non-UNIX computers. In 1994, Mosaic dominated the use of the Web by personal computers. However, by 1996, Rafter (1996) notes that Mosaic's popularity dropped rapidly when Netscape appeared on the market. Mosaic was a "hassle to install," slow, and lacked an integrative e-mail function (p. 47). However, Mann (1996) predicts that with all the improvements in Microsoft's Explorer, Netscape may soon follow the path of Mosaic.

Since January 1994, Pitkow (Pitkow \& Kehoe, 1997) has been involved in surveying the Web. To date, at least seven comprehensive surveys have been completed. The results of these surveys (and future ones) can be found on their web page:

\section{http://www.cc.gatech.edu/gvu/user-surveys/}

The data offer implications that are clearly political and economic. However, the key factor that influences the popularity of the WWW is user-friendliness. With user-friendly software and access, we see the emergence of social work activity on the Internet.

\section{THE INTERNET AND SOCIAL WORK: A PERSONAL PERSPECTIVE}

A vast array of social work Web sites have sprung up. The first systematic social work invasion of Web service was in educational institutions. Michael McMurray (Colorado State University) was the first, most notable effort. A long-lived and well-managed example is the University of South Carolina's SWAN (Social Work Access Network). At the time of this writing well over $25 \%$ of all accredited social work academic programs have Web sites. Clearly, Web pages that are owned and operated by large institutions are the most reliable. Nevertheless, I believe the future power of the Web lies elsewhere.

Although psychotherapy on the Internet existed prior to the popularity of the Web, employing the Web as a medium of psychotherapy has mushroomed. During a recent survey, well over 1,000 psychotherapists were capitalizing on the Web. Each time Marson and Brackin (1996a; 1996b; 1996c) study psychotherapy on the Web, the number of therapists increases. NASW News is chronicling efforts of private practitioners in this arena. Clearly, the Web will have a profound effect on future strategies for psychotherapy and other forms of social work practice. For example, Schein-Levi and Pollack (1997) demonstrate how social workers can employ the Web for enhancing parenting skills.

According to Anderson et al. (1 995), the most widespread use of the Internet among the general public is not browsing the Web, but email and listservs. Marson (1997) confirms this finding among social workers. A personal history will help explain the importance of these two uses. When I first learned of access to the Internet, I also learned about listservs and immediately searched for a listserv that addressed social work issues. In my search, I discovered the Social Work discussion list [SOCWORK]. SOCWORK started as an idea for introducing students at the School of Social Work, University of Toronto, to computer communication technology. Bellamy (1987), and Bellamy and Mielniczuk (1988) offer historical details of how and why the list became operational on February 3, 1988. It began with 11 students and four faculty and staff. Within four months there were 20 members. By May 1989 there were approximately 75 members and a new management under the watchful eye of Harry Chaiklin at the University of Maryland. It was about this time that I discovered SOCWORK and joined the list when there were fewer than 80 subscribers.

During Harry’s tenure, two major developments occurred. First, after much prodding among various members of the listserv, the Council on Social Work Education [CSWE] subscribed to SOCWORK. Second, staff from the National Association of Social Workers WASW] subscribed. Participation by our two major professional organizations established an aura of legitimacy and personal subscriptions to SOCWORK surged. Later, when the subscribers grew to approximately 700 in the spring of 1995, Cindy Jones from the University of Arkansas inherited SOCWORK. Soon SOCWORK had over 
1,000 subscribers and many thought the listserv was out of control. As a result, in the fall of 1996, Ogden Rogers from the University of Wisconsin at River Falls became the new manager. The number of subscribers shrank to less than 300, but SOCWORK became more manageable. Listservs are now flourishing and are being systematically evaluated for their contribution to the profession. Berman (1996) provides an excellent example of such research in his analysis of two listservs [SOCWORK and ABUSEL].

SOCWORK spawned a host of other social work listservs. One of the first to follow SOCWORK was BPD [The Association of Baccalaureate Program Directors]. Other listservs include:

\author{
Computer Use in Social Services (CUSSN) \\ Feminist Social Work \\ Field Education \\ Human Services Information Technology Association \\ International Social Work \\ Philosophy and Science of Social Work \\ Rural Social Work \\ Student Social Work List
}

Noticing the congressional proposals to decentralize social services, the Consortium of State SOCWORK Listservs was founded in 1993 by Steve Marson at the University of North Carolina at Pembroke. With decentralization, each state has gained greater control over social service resources.

The direction of the services may greatly depend on the ability of state social workers to spread knowledge to grassroot organizations and to lobby the state house in a favorable direction. State social work listservs should prove to be vital for the speedy dissemination of needed information.

Social workers have a long history of technology avoidance. This avoidance was first noted by Richmond (1911) when she had to encourage turn-of-the-century social workers to exploit the telephone as a tool for practice. Toward the end of this century and with the inaugural issue of a newsletter entitled Computer Use in Social Services Network (CUSSN), Dick Schoech (1981) took Richmond's place as the nurturer of technology. Schoech's newsletter evolved into a journal entitled Computers in Human Services (Schoech, 1985), which continues to lay the ground work for integrating and advancing computer technology in social work. For example, it served as a platform for Hanna (1995) to report on early efforts to combine and link many existing electronic networks through the Internet. Prior to this effort, electronic and political barriers prohibited members of one network from sending email or conference with members from other human services networks.

\title{
INTERNET AND KEY SOCIAL WORK ORGANIZATIONAL EVENTS
}

Four happenings in recent history have had an influence on social work and the Internet. In the late 80s, CSWE board members and NASW staffs became active on the Internet. A CSWE staff member coordinated a meeting of two Internet enthusiasts. Although they communicated often over the Internet, they first met face to face at the CSWE 1990 Annual Program Meeting [APM]. Here, they gave birth to the Baccalaureate Program Directors Association's Committee on Information Technology and Social Work Education [CIFTSWE]. In 1992, the unofficial committee offered its first workshop at the BPD annual conference. At the 1995 APM, the committee became an important part of BPD's table of organization as a standing committee.

The most stirring moment in the short history of technology and social work professional organizations was at the 1992 APM. Marshall Smith requested the floor in an open meeting of CSWE's Accreditation Board. In a very eloquent, short, but powerfully moving speech, Marshall expressed 
the importance of the Internet for the accreditation process. He made a plea that board members consider accepting self-studies via the Internet. Marshall was ahead of his time. Now we are wagering on which school will take the bold step to be the first the submit a self-study via electronic means. One positive intermediate step was taken to achieve this goal. Through the advocacy of BPD's Committee on Information Technology and Social Work Education, CSWE's Directory of Colleges and Universities with Accredited Social Work Degree Programs included e-mail addresses. Soon web page locations will be published in the Directory. These actions lay the ground work for the electronic transmission of selfstudies and a more efficient means of educational research. Technical and confidentiality problems related to document transfer are on the verge of being resolved.

Third, in early 1995, Rita Vandivort, of the NASW national office, established a listserv for technologically capable social workers to plan an Internet symposium at the upcoming NASW conference. As a staff member of NASW, she was able to acquire funds to put together an impressive Internet demonstration facility at the Philadelphia conference. Members of the technology committee involved in the planning were overwhelmed and profoundly impressed with the Internet resources that Rita was able to pull together. It was a success beyond anyone’s imagination. Since the Philadelphia conference, the use of an Internet lab continues to be an important feature of the NASW annual conference. Perhaps more than any single event in the history of social work and the Internet, the lab at the NASW conference has had the greatest influence on the utilization of the Internet among seasoned social work practitioners.

Fourth, in the fall of 1992, Ogden Rogers proposed that SOCWORK subscribers who were also CSWE members meet face-to-face. Ogden dubbed the group “OffLine.” Subscribers/CSWE members had been communicating with each other on a wide variety of levels. Close friendships were established, accreditation consultation support was given, and in some cases enemies were made! Steve Marson organized this group's first "get-together" during the 1993 APM in New York. The second get-together in 1994 in Atlanta was also a great success. During a SOCWORK discussion, subscribers decided to formalize OffLine in order to avoid scheduling conflicts. Since the formalization of Offline, the "social” get-togethers have been well attended and led to more serious academic conferences.

\section{RECOMMENDATIONS}

The profound influence of the Internet and technologies that the Internet will spawn in the future is undisputed (Anderson et al., 1995; Neubarth, 1996). Social work and the entire social welfare system will not escape utilizing the Internet anymore than social workers were able to escape the use of the telephone during Richmond's era. As a result, we have an ethical obligation to systematically encourage others to employ the Internet in their daily activities. Competence and comfort with the Internet leads to and enhances one's creativity in using the Internet, which in turn leads to improved human services. Such statements are grandiose and easy to state. How does one operationalize this?

Reading and recalling recent history is a good place to start. Our short history and experience offers some simple guidelines:

- Like Richmond, professors and field instructors must shepherd their students (particularly non-traditional students) into feeling comfortable with the Internet.

- Leaders both in education and practice must share their ideas by writing, presenting papers at conferences, and offering workshops about technology. Tom Hannah, Dick Schoech and Rita Vandivort are good conternporary role models for the rest of us.

- Leaders of professional organizations must be nurtured into accepting that computer technology and the Internet have vast implications for their organization's benefit. This can only be accomplished by a one-by-one strategy and face-to-face interaction. In addition, 
technologically competent professionals must organize themselves to vote for leaders who recognize the importance of the Internet. Actions like Marshall Smith's speech is a good illustration. Members of CIFTSWE make efforts to support candidates that have a history of supporting technology.

- Leaders of professional organizations should be shown that technology committees made up of volunteers are a cost effective manner of spreading the advantages that the Internet and computers have for human services. The development and actions of CIFTSWE provide an excellent example.

- Workshops must be freely offered in a nonintimidating manner to those professionals and educators who are technophobic. CIFTSWE's annual workshops are good illustrations of an effective strategy.

- Technophobic professionals must be approached in the same manner as Richmond approached social workers at the turn of the century. They must be nurtured, reassured, and shown that such technology is not dehumanizing but improves the quality of care. Vandivort's coordination of NASW's Internet lab at annual conferences represents an excellent example.

- Technologically competent professionals should meet socially (i.e., OffLine) and professionally (i.e., conferences). These meetings must be used to share ideas on effective methods of spreading the good news of technology and the Internet.

- Technologically capable human service professionals need to lead the way to make Internet technology user-friendly and practical. As stated earlier, CIFTSWE is developing a structure for the confidential transmission of CSWE self studies and research via the Internet.

\section{CONCLUSIONS}

The key to advancing the Internet in social work is the theme found in the history of the development of the Internet. As a social worker, two aspects of Internet history are striking. The concept of "unintended consequcnces" is first apparent. The present use of the Internet is nothing like the original notion expected by its designers. A vast array of commercial and non-commercial applications for social work practice now exist. We are just witnessing the tip of the iceberg. Second, and closely related to the concept of unintended consequences, is social work values. The values to which most social workers cling are contrary to the values behind the original design of the Internet. Recall that the original intent of the Internet was to deliver weapons of mass destruction. Now, we see social workers employing it as a system to deliver social services.

The success of the Internet must be attributed to the cooperative nature of it's users. I find that the massive level of cooperation found in the Internet is unprecedented in the twentieth century. In the end, social work success in employing the Internet will be limited only by the cooperative nature of those using it in practice and research. 


\section{REFERENCES}

Anderson, R.H., Bikosn, T. K., Law, S. A. \& Mitchell, B.M. (1995). Universal Access to E-Mail: Feasibilitv and Societal Implications. Santa Monica: Rand Corporation.

Bellamy, D. (1987). Innovative applications of computer technology in social work. Paper presented at the Conference of the Canadian Association of Schools of Social Work, Learned Societies Meeting, Hamilton, Ontario, June 7.

This is an electronic version of "A Selective History of Internet Technology and Social Work," that was published in Computers in Human Services, 14:2, 35 - 49. The article is available online at the following URL: http://dx.doi.org/10.1300/J407v14n02_03 